\title{
ANALISIS KEPUASAN DAN LOYALITAS PELANGGAN PENGARUHNYA TERHADAP KEPUTUSAN MENGGUNAKAN JASA LAYANAN ONLINE (GRAB) DI WILAYAH KOTA MEDAN
}

\author{
Austin Alexander Parhusip \\ Fakultas Ekonomi dan Bisnis, Program Studi Manajemen, Universitas Potensi Utama, \\ Jl. K.L.Yos Sudarso, Tj. Mulia, Medan Deli, Kota Medan-20241Telp: (061) 6640525, \\ e-mail: austin alexander@potensi-utama.ac.id / Austin_wisehorse@yahoo.co.id
}

\begin{abstract}
ABSTRAK
Dalam studi ini bermaksud untuk menganalisis kepuasan pelanggan dan loyalitas atas keputusan untuk menggunakan layanan online (grab) dan bagaimana pengaruh kepuasan pelanggan dan loyalitas terhadap keputusan untuk menggunakan layanan layanan online (grab) secara partial, serta pengaruh kepuasan dan loyalitas pelanggan secara simultan terhadap keputusan menggunakan jasa layanan online (grab). Jenis penelitian yang digunakan dalam riset ini adalah survei. Populasi pada penelitian ini adalah seluruh masyarakat yang berada di kota Medan yang pernah melakukan pembelian atau menggunakan aplikasi grab. Metode purposive sampling yang digunakan dalam pengambilan sampel sebanyak 100 orang. Teknik pengumpulan data menggunakan kuesioner yang telah diuji validitas dan reliabilitasnya. Teknik analisis data yang digunakan untuk menjawab hipotesis adalah regresi berganda. Hasil penelitian ini menunjukkan bahwa: terdapat pengaruh positif kepuasan yang berubah-ubah terhadap keputusan pembelian online (grab), terdapat pengaruh positif variabel loyalitas terhadap keputusan pembelian online (grab. Secara simultan kepuasan, dan loyalitas berpengaruh positif terhadap minat beli secara online.

Kata Kunci : Kepuasan, Loyalitas, Keputusan Pembelian, Tranportasi Online
\end{abstract}

\begin{abstract}
This study intends to analyze customer satisfaction and loyalty on the decision to use online services (grab) and how the influence of customer satisfaction and loyalty on the decision to use online services (grab) partially, as well as the effect of simultaneous customer satisfaction and loyalty on the decision to use online services (grab). The type of research used in this research is a survey. The population in this study were all people in the city of Medan who had made a purchase or used the grab application. Purposive sampling method used in the sampling of 100 people. The data collection technique uses a questionnaire that has been tested for validity and reliability. The data analysis technique used to answer the hypothesis is multiple regression. The results of this research show that: there is a positive influence of varying satisfaction on online purchasing decisions (grab), there is a positive influence of loyalty variables on online purchasing decisions (grab. Simultaneously, satisfaction and loyalty have a positive effect on online purchase intention).
\end{abstract}

Keywords: Satisfaction, Loyalty, Purchase Decision, Online Transportation

\section{A. Latar Belakang}

\section{PENDAHULUAN}

Di era digitalisasi kebutuhan manusia saat ini semakin bervariasi serta pengembangan bisnis saat ini adalah produk dan layanan yang sangat cepat sehingga strategi pemasaran dibutuhkan hak untuk menangani persaingan bisnis dan mempertahankan jumlah pelanggan yang ada atau lebih, terutama jumlah pelanggan. Semacam layanan bisnis online (go-jek) yang baru-baru 
ini dibahas oleh berbagai pihak. Ada banyak hal yang mempengaruhi konsumen untuk menggunakan layanan layanan online (Grab).

Transportasi adalah sarana yang digunakan untuk memindahkan manusia atau barang dari satu tempat ke tempat lain dengan menggunakan kendaraan yang digerakkan oleh manusia atau mesin (https://wikipedia.com), transportasi dapat dibagi menjadi dua jenis, yaitu transportasi umum dan pribadi. Transportasi umum pertama kali hanya berbasis konvensional di mana untuk mendapatkan layanan, penumpang harus menunggu di jalur dan di terminal. Kategori peralatan transportasi konvensional sering digunakan di kota Medan, yaitu, transportasi umum, taksi becak, dan becak sepeda motor.

Bersamaan dengan pertumbuhan penampilan inovasi di bidang transportasi yang juga didukung oleh pertumbuhan teknologi, itu adalah transportasi online. Transportasi online atau mereka yang mengatakan dengan perusahaan jaringan transportasi adalah penunjukan menjelaskan pengaturan berbagi kendaraan (berbagi kendaraan) permintaan berbasis dalam waktu singkat dan bertepatan yang terhubung melalui web dan aplikasi seluler (https: // en. Wikipedia.org). Layanan transportasi online ini relatif baru di Indonesia dan hanya beberapa industri yang menyediakan layanan ini. Transportasi online itu sendiri dimulai di Indonesia pada tahun 2010 dan menjadi terkenal sejak 2014.

Salah satu perusahaan transportasi online populer di Indonesia adalah grab. Grab adalah perusahaan transportasi online yang berasal dari Malaysia sejak 2012. Awalnya ambil tersedia di enam negara di Asia Tenggara, yaitu Malaysia, Singapura, Thailand, Vietnam, Indonesia, dan Filipina. Namun, kali ini Grab telah berhasil mengembangkan bisnisnya di negara-negara di luar wilayah Asia Tenggara seperti Cina, Amerika Serikat, Denmark dan India yang sekarang telah mencapai 50 juta pengguna (https://grab.careers), tujuan dari Perusahaan menjangkau dari masalah dengan kurangnya minat publik untuk menggunakan transportasi umum konvensional karena kurangnya jaminan keamanan, rendahnya kualitas transportasi umum, dan biaya musik mitin dengan transportasi umum konvensional.

Namun, grab bukan satu-satunya perusahaan transportasi online di Kota Medan. Munculnya beberapa merek transportasi online lainnya seperti Go-Jek, Uber, On-Jek, Indotiki, dan lainnya dengan beberapa kesamaan dalam hal penawaran yang diberikan dan kemudahan akses menyebabkan pengguna layanan mudah untuk memindahkan aplikasi. Hal ini membuat persaingan di dunia bisnis di bidang transportasi online, semakin sengit dan menyebabkan pebisnis mencoba lebih untuk mempertahankan posisi mereka dalam kondisi pasar yang semakin kompetitif. Ada dua cara yang dapat dilakukan perusahaan untuk mempertahankan posisinya, yaitu dengan memperoleh pelanggan baru dan memelihara pelanggan yang sudah ada. Pilihan untuk mempertahankan pelanggan yang sudah ada dianggap lebih menguntungkan, karena perusahaan berinvestasi lebih dari lima kali untuk mendapatkan pelanggan baru daripada memelihara pelanggan (Kheng, Mahamad, Mosahab, \& Ramayah, 2010). Oleh karena itu, penentuan strategi dalam membangun dan memelihara loyalitas pelanggan adalah prioritas tertinggi bagi setiap perusahaan untuk menghadapi industri dengan pertumbuhan yang cepat. Ini juga didukung oleh penelitian yang dilakukan oleh AtchariyaChanvanich, Sohenara, \&,Okada (2008) yang mengatakan bahwa salah satu faktor yang menentukan perusahaan lebih unggul dari perusahaan lain dapat dilihat dari bagaimana perusahaan mempertahankan konsumen untuk terus berbelanja atau menggunakan layanan korporat karena Dalam pemasaran lapangan, biaya tarif maaf lebih tinggi daripada biaya penahan pelanggan (Griffin, 2003).

Berdasarkan survei sederhana yang dilakukan oleh para peneliti dengan mengajukan pertanyaan kepada sepuluh pengemudi dengan tidak pernah atau tidak mereka bertemu dengan penumpang yang sama. Delapan dari sepuluh pengemudi mengatakan bahwa mereka telah bertemu dengan penumpang yang sama setidaknya sekali dalam periode dua minggu (survei, Juli 2020). Data menunjukkan bahwa perilaku penggunaan layanan berulang pada grab konsumen cukup tinggi.

Tinjauan umum pembelian berulang sering menunjukkan bahwa konsumen merasa nyaman untuk membeli di perusahaan yang sama, tetapi tidak dapat digunakan sebagai kesimpulan bahwa hubungan jangka panjang antara perusahaan dan konsumen telah 
dibentuk (Webster, 1992). Sebaliknya, perilaku setia menjelaskan mengapa konsumen tidak mudah dipengaruhi oleh produk alternatif atau layanan lain (Dick \& Basu 1994; Shankar, Smith, \& RangasWamy 2003). Jadi dapat disimpulkan bahwa loyalitas konsumen adalah komitmen yang sangat kuat untuk membeli kembali layanan yang disukai dan konsisten di masa depan yang mengarah pada pembelian merek yang sama berulang kali, meskipun pengaruh situasional dan pemasaran memiliki potensi untuk menyebabkan perubahan perilaku.

Ada beberapa penelitian sebelumnya tentang loyalitas. Boora \& Sigh (2011), mengatakan bahwa loyalitas konsumen secara universal diakui sebagai aset berharga di pasar yang semakin kompetitif. Diakui sebagai aset perusahaan karena loyalitas pelanggan bersifat kumulatif dan jangka panjang. Ini berarti bahwa loyalitas konsumen berbanding lurus dengan intensitas perilaku pembelian konsumen di perusahaan tertentu (Carrillat, Francois, \& Mulki, 2009). Selain itu, manfaat perusahaan akan diperoleh ketika mampu mempertahankan konsumen, termasuk konsumen yang loyal akan mengatakan hal-hal positif tentang perusahaan kepada orang lain (Boulding, Staelin, Karla, \& Zeithaml, 1993), merekomendasikan perusahaan kepada orang lain (Parasuraman \& Zeithaml, 1991a), membayar lebih untuk tetap berhubungan dengan perusahaan (Marzursky \& Labarbera, 1983).

Selanjutnya, ada faktor-faktor yang berkontribusi pada loyalitas pelanggan terhadap suatu produk dan layanan. Faktor-faktor ini termasuk kualitas layanan (Carrillat, Francois, \& Mulki, 2009), Trust (Upamanyu \& Marthur, 2012), Nilai (Neal, 1999), Komitmen (Morgan \& Hunt, 1994), dan Kepuasan (Vikas \& Kamakura, 2001; Szymanski \& Henard, 2001). Kepuasan umumnya adalah pendorong utama loyalitas dalam perilaku konsumen. Konsep layanan menyatakan bahwa perilaku setia pada konsumen terbentuk karena pengalaman perasaan yang puas yang dihasilkan oleh pengalaman positif Perusahaan dan merupakan perilaku pendahulu sebelum perilaku loyal yang muncul dalam konsumen (Olsen, 2007). Perasaan puas yang dialami oleh konsumen menurut Gounis, Dimitriadis, \& Vlasis (2010), dibentuk melalui evaluasi afektif di mana setelah membeli konsumen yang melakukan penilaian kognitif pengalaman ketika melakukan pembelian dan merupakan faktor penting yang mempengaruhi keberhasilan suatu perusahaan (Cronim \& Taylor, 1992).

Ada beberapa penelitian yang berkaitan dengan kepuasan. Hasil penelitian yang dilakukan oleh Astuti, Zakaria, \& Tri (2013) menyatakan bahwa variabel kualitas layanan, persepsi harga, dan citra merek secara bersamaan memiliki pengaruh yang signifikan terhadap kepuasan konsumen di pengguna bus Jogja. Selain itu, penelitian yang dilakukan oleh Citrawan (2013) mengatakan bahwa ada pengaruh yang signifikan antara kualitas yang termasuk responsif, keandalan, empati (empathy), jaminan (assurance), dan bukti fisik (tangibles) ke tingkat kepuasan pelanggan bengkel terang sepeda motor Semarang.

Beberapa studi empiris mengatakan bahwa ada dampak atau efek kepuasan dengan loyalitas konsumen. Penelitian yang dilakukan oleh Widyaningtyas (2010) memiliki beberapa kesimpulan dari hasil penelitian, (1). Kualitas layanan terbukti memiliki pengaruh pada pengguna kepuasan konsumen layanan transportasi Kereta Api Harina. (2). Ada pengaruh antara harga tiket untuk kepuasan pelanggan (3). Kepuasan konsumen sebagai variabel intering antara kualitas konsumen dan loyalitas berarti jika kualitas layanan meningkat, kepuasan konsumen juga tinggi sehingga akan mempengaruhi loyalitas konsumen. (4). Kepuasan konsumen adalah variabel intervensi antara harga tiket dan loyaltas konsumen berarti bahwa harga tiket yang ditawarkan lebih bervariasi, kepuasan konsumen juga tinggi sehingga akan mempengaruhi loyalitas konsumen. Dengan demikian dapat disimpulkan bahwa dugaan pengaruh antara kepuasan pelanggan dengan loyalitas konsumen dapat diterima. Selanjutnya, hasil penelitian yang dilakukan oleh Halida (2013) mengatakan bahwa pengalaman merek secara signifikan berpengaruh positif terhadap kepuasan pelanggan Bank Islam. Kemudian, kepuasan konsumen memiliki efek positif yang signifikan terhadap loyalitas dan kepuasan konsumen adalah faktor yang perlu dipenuhi terlebih dahulu sehingga konsumen menjadi loyal.

Berdasarka paparan di atas, maka akan dilakukan penelitian tentang: "Analisis Kepuasan Dan 
Loyalitas Pelanggan Pengaruhnya Terhadap Keputusan Menggunakan Jasa Layanan Online (Grab) Di Wilayah Kota Medan"

\section{B. Masalah Penelitian}

Adapun pokok permasalahan dalam penelitian ini dapat dirumuskan sebagai berikut yaitu:

1) Apakah kepuasan berpengaruh terhadap keputusan menggunakan jasa layanan online (Grab)?

2) Apakah loyalitas berpengaruh terhadap keputusan menggunakan jasa layanan online (Grab)?

3) Apakah kepuasan dan loyalitas berpengaruh terhadap keputusan menggunakan jasa layanan online $(\mathrm{Grab})$ ?

\section{Tujuan dan Manfaat Penelitian}

\section{Tujuan Penelitian}

Sehubungan dengan masalah yang dijelaskan di atas, tujuan penelitian ini adalah:

a. Untuk mengetahui pengaruh kepuasan terhadap keputusan menggunakan jasa layanan online (Grab)

b.Untuk mengetahui pengaruh loyalitas terhadap keputusan menggunakan jasa layanan online (Grab)

c. Untuk mengetahui pengaruh kepuasan dan loyalitas terhadap keputusan menggunakan jasa layanan online (Grab)

\section{Manfaat Penelitian}

Dari hasil penelitian yang dilakukan, penulis berharap dapat memberikan manfaat bagi berbagai pihak, termasuk:

a. Bagi perusahaan; Hasil penelitian ini diharapkan mendapat umpan balik untuk mengetahui kepuasan, loyalitas, dan keputusan menggunakan layanan online (grab) di kota Medan.

b. Bagi masyarakat; Hasil penelitian ini diharapkan dapat digunakan selain informasi dan pengetahuan yang menguntungkan mereka yang ingin mencari tahu tentang loyalitas, kepuasan pelanggan, hal-hal yang memengaruhinya dan dampaknya pada keputusan untuk menggunakan layanan layanan online (grab).

c. Bagi penulis; Hasil penelitian ini diperkirakan akan memperluas wawasan berpikir penulis tentang kepuasan, loyalitas dan pengaruh pada keputusan untuk menggunakan layanan online (grab).

\section{A. Landasan Teori}

\section{LANDASAN TEORI}

Schiffman dan Kanuk (2012) menyatakan bahwa loyalitas adalah hasil akhir yang diharapkan dari pembelajaran pelanggan yang terdiri dari kecenderungan sikap dan perilaku suatu merek dan keduanya dapat diukur sebagai niat pembelian dan pembelian kembali perilaku. Sedangkan menurut Hawkins, Motherbaugh, \& Best (2007) mengatakan bahwa loyalitas didefinisikan sebagai bentuk yang hampir sama dengan persahabatan. Loyalitas muncul selama konsumen mengidentifikasi, dimana konsumen percaya bahwa merek mempengaruhi atau meningkatkan beberapa aspek konsep diri di dalam konsumen. Biasanya konsumen menggunakan ekspresi seperti "Saya percaya pada merek ini" atau "Saya suka berbelanja di toko ini".

Didasarkan dari definisi diatas maka dapat disimpulkan bahwa loyalitas pelanggan merupakan merupakan hasil akhir yang diharapkan dari pembelajaran pelanggan yang terdiri dari kecenderungan sikap dan perilaku terhadap suatu merek dan keduanya dapat diukur melalui keterikatan, kecenderungan psikologis, dan komitmen mendalam dalam diri pelanggan terhadap sebuah merek yang terlihat melalui perilaku pembelian berulang dan memperluas penggunaan produk atau penyedia layanan yang sama dan konsisten di masa depan meskipun perubahan, persaingan pasar, maupun pengaruh-pengaruh situasional berpotensi menimbulkan perubahan perilaku. Hal ini terbentuk karena adanya sikap positif pelanggan seperti, cinta, kepercayaan, dan kesediaan untuk memaafkan jika terjadi kegagalan terhadap produk atau jasa tertentu, serta kesediaan untuk mengatakan hal-hal positif kepada rekannya. 
Oliver (2015) menjelaskan bahwa kepuasan merupakan respon pelanggan atas pemenuhan yang dialaminya. Didasarkan oleh penilaian bahwa fitur produk atau layanan, itu sendiri tersedia (menyediakan) tingkat pemenuhan konsumsi yang sesuai. Selanjutnya, Kotler (1996) mengungkapkan bahwa kepuasan pelanggan merupakan hasil dari kinerja perusahaan yang dirasakan oleh pembeli yang terpenuhi harapannya, hasil dari pembeli yang merasa sangat puas adalah mereka kurang peka terhadap harga, tetap menjadi pelanggan dalam waktu yang lama, membeli produk tambahan ketika perusahaan memperkenalkan produk yang berkaitan atau versi perbaikan, dan memberikan informasi yang menguntungkan mengenai perusahaan kepada rekannya.

Berdasarkan definisi diatas maka dapat disimpulkan bahwa inti dari kepuasan pelanggan adalah perasaan akan kebutuhan yang terpenuhi dan didasarkan oleh perbandingan pelanggan akan kinerja produk atau pelayanan jasa dengan harapan akan produk atau pelayanan jasa sebelumnya. Apabila harapan pelanggan tercapai atau melebihi ekspektasi maka pelanggan merasa puas, perasaan puas ini memungkinkan pelanggan untuk melakukan pembelian berulang dan memberikan informasi positif mengenai perusahaan kepada rekannya.

Kotler dan Keller (2012) kepuasan itu mencerminkan terhadap penilaia individu pada produk yang dirasakan kinerja dibandandingkan dengan harapan. Pelanggan akan kecewa jika kinerjanya kurang dari harapan, pelanggan akan puas jika harapan nya terpenuhi bahkan melebihi harapannya. Menurut Anderson dan Ullivan dalam Hoq (2010) Kepuasan pelanggan mempunyai dampak positif terhadap loyalitas karena menurut mereka niat pembelian kembali positif dipengaruhi oleh kepuasan dan pelanggan akan tetap setia kepada perusahaan ketika ada peningkatan dalam tingkat kepuasan. Sama dengan Bontis et dalam Hoq (2010) mengemukakan bahwa kepuasan pelanggan dalam meningkatkan reputasi dalam industry, sedangkan Anderson dan Sullivan dalam Hoq et al mengatakan bahwa kepuasan pelanggan mengarah pada meningkatkan reputasi, dan loyalitas pelanggan.

Armistead dan Clark (1996:5-7) mengatakan ada beberapa keuntungan untuk menyediakan layanan yang memuaskan pelanggan. Manfaat pertama dan terbesar adalah kepercayaan pelanggan. Bahkan, pelanggan menilai kualitas produk mereka dengan melihat dan memahaminya. Keuntungan kedua adalah pelanggan mendapatkan nilai maksimal dari pembelian mereka dan memungkinkan mereka dengan cepat dan mudah menggunakan semua manfaat dari produk yang mereka beli. Manfaat produk dan layanan yang diberikan kepada pelanggan harus mengarah pada loyalitas pelanggan yang lebih besar. Ada dua jenis kepuasan pelanggan: 1 . Kepuasan fungsional adalah kepuasan yang diperoleh dari fungsi atau penggunaan produk. Misalnya dengan makan, orang menjadi kenyang dan sehat. 2. Kepuasan psikologis adalah kepuasan yang diperoleh dari atribut-atribut tidak berwujud dari produk yang dibeli. Misalnya, orang bangga mengendarai mobil BMW..

\section{B. Kerangka Konseptual}

Berdasarkan penjelasan yang dikemukakan diatas, maka kerangka konseptual variabel independen dan dependen dalam melihat pengaruh antara variabel baik secara simultan maupun parsial dapat dilakukan pada gambar paradigma dibawah ini:

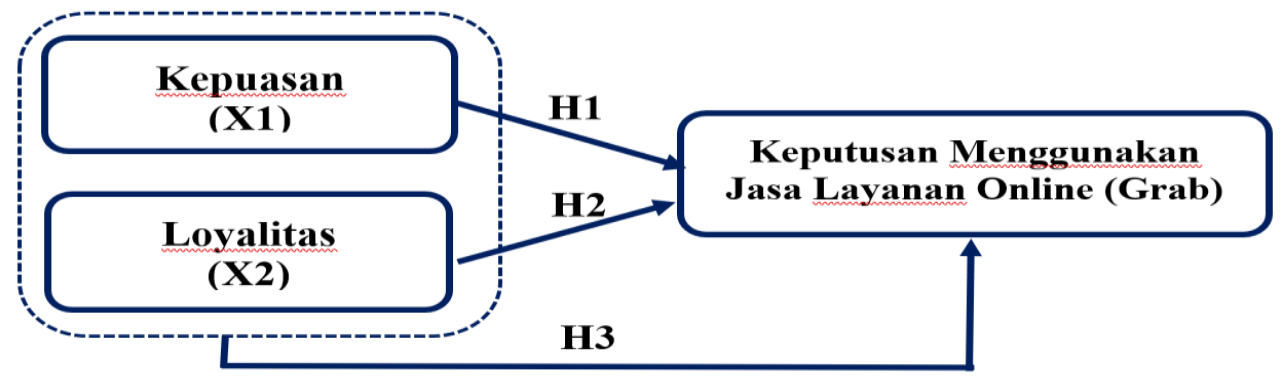

Gambar 1. Paradigma Penelitian

Sumber : Data Diolah 


\section{Hipotesis}

Hipotesis merupakan jawaban sementara terhadap rumusan masalah. Hipotesis juga menyatakan hubungan yang diduga secara logis antara dua variabel atau lebih. Adapun hipotesis dalam penelitian ini adalah sebagai berikut :

1. Kepuasan berpengaruh secara parsial terhadap keputusan menggunakan jasa layanan online (Grab).

2. Loyalitas berpengaruh secara parsial terhadap keputusan menggunakan jasa layanan online (Grab).

3. Kepuasan, Loyalitas, secara simultan terhadap keputusan menggunakan jasa layanan online (Grab).

\section{METODOLOGI PENELITIAN}

\section{A. Definisi Operasional}

\begin{tabular}{|c|c|c|c|}
\hline Variabel & Definisi & Indikator & Skala \\
\hline \multirow{3}{*}{$\begin{array}{l}\text { Kepuasan } \\
\text { Pelanggan } \\
\text { (X1) }\end{array}$} & \multirow{3}{*}{$\begin{array}{l}\text { Kepuasan konsumen adalah } \\
\text { perasaan seseorang yang sudah } \\
\text { mendapatkan hasil yang diinginkan } \\
\text { saat berharap. (Kotler 2001) }\end{array}$} & Kesesuaian akan harapan & \multirow{3}{*}{ Likert } \\
\hline & & $\begin{array}{l}\text { Persepsi kinerja jasa layanan yang } \\
\text { bagus }\end{array}$ & \\
\hline & & Penilaian pelanggan akan suatu jasa & \\
\hline \multirow{3}{*}{$\begin{array}{l}\text { Loyalitas } \\
\text { Pelanggan } \\
\quad \text { (X2) }\end{array}$} & \multirow{3}{*}{$\begin{array}{l}\text { Loyalitas pelanggan mencerminkan } \\
\text { niatan dalam berperilaku (intended } \\
\text { behavior) dengan suatu produk } \\
\text { atau jasa. (Selnes (1993) }\end{array}$} & $\begin{array}{l}\text { Kesetiaan terhadap pembelian suatu } \\
\text { barang atau jasa }\end{array}$ & \multirow{3}{*}{ Likert } \\
\hline & & $\begin{array}{l}\text { Ketahanan terhadap pengaruh yang } \\
\text { negative mengenai perusahaan }\end{array}$ & \\
\hline & & $\begin{array}{l}\text { Mereferensikan secara total esistensi } \\
\text { perusahaan }\end{array}$ & \\
\hline \multirow{3}{*}{$\begin{array}{l}\text { Keputusan } \\
\text { Pembelian/ } \\
\text { Menggunakan } \\
\text { Layanan } \\
\text { Online } \\
\text { (Y) } \\
\end{array}$} & \multirow{3}{*}{$\begin{array}{l}\text { Keputusan pembelian adalah tahap } \\
\text { dimana pembeli sudah menentukan } \\
\text { pilihan dan melakukan pembelian } \\
\text { produk atau jasa, serta } \\
\text { mengkonsumsinya.(Suharno } \\
(2010: 96)\end{array}$} & $\begin{array}{l}\text { Keyakinan akan sebuah produk atau } \\
\text { jasa }\end{array}$ & \multirow{3}{*}{ Likert } \\
\hline & & Kebutuhan akan suatu produk atau jasa & \\
\hline & & $\begin{array}{l}\text { Keinginan untuk membeli sebuah } \\
\text { produk atau memakai sebuah jasa }\end{array}$ & \\
\hline
\end{tabular}

\section{B. Tempat dan Waktu Penelitian}

Penelitian ini diadakan di kota Medan dengan sampel adalah pengguna dari aplikasi transportasi online grap di kota Medan dari berbagai tingkat usia, jenis kelamin, pendidikan, profesi, keuntungan per bulan responden.

\section{Populasi dan Sampel Penelitian}

100 orang warga di Medan yang mengetahui dan menggunakan aplikasi tranportasi online khususnya aplikasi Grab. Teknik penarikan sample pada penelitian ini adalah dengan menggunakan teknik. Aksidental didasarkan pada kemudahan (convenience) dimana sample dapat terpilih karena berada pada waktu, situasi dan tempat yang tepat (Prasetyo \& Lina, 2005). Data diambil dengan menyebarkan kuesioner atau angket kepada semua pengguna aplikasi Grab.

\section{Teknik Pengumpulan Data}

Dalam data penelitian ini, terdapat dua bagian yaitu data primer dan data sekunder. Data primer disini bisa seperti hasil wawancara pribadi, observasi dan kuesioner. Sedangkan data sekunder sendiri biasanya berupa bukti, catatan atau laporan historis yang sudah tersusun dalam arsip yang bisa di publikasi atau tidak. Teknik pengumpulan data dalam penelitian ini 
menggunakan instrumen penelitian berupa kuesioner. Alat ukur variabel penelitian ini menggunakan skala Likert. Cooper, et al (2017) mengemukakan bahwa Skala likert adalah variasi yang paling sering digunakan dari skala penilaian yang dijumlahkan. Skala penilaian yang dijumlahkan terdiri atas pernyataan yang mengekspresikan baik sikap mendukung dan tidak mendukung dari objek kepentingan. Tanggapan terhadap respons pada skala penelitian ini menggunakan 5 (lima) opsi, yaitu, sangat setuju (SS), kurang setuju (KS) sangat setuju (SS). Skor berkisar antara 5 dan 1, semakin besar nilai skor, semakin besar tingkat tinggi tingkat prokrastinasi akademik, adversity quotient, pemilihan SS dari 5, skor 4, KS mendapat skor 3, KS mendapat skor 3, TS mendapat skor 2, dan STS mendapat skor 1.

\section{E. Teknik Analisis Data}

Analisis regresi digunakan untuk memprediksi seberapa jauh perubahannya dalam nilai variabel dependen, jika nilai variabel independen dimanipulasi atau diubah. Analisis regresi linier berganda $\mathrm{Y}=\mathrm{a}+\mathrm{b} 1 \mathrm{X} 1+\mathrm{b} 2 \mathrm{X} 2+\varepsilon$. Di mana: $\mathrm{Y}=$ Keputusan menggunakan layanan online Grab, X1 = Orientasi Belanja, X2 = Kepercayaan Online, X3 = Pengalaman Pembelian, $\varepsilon=$ Penambahan variabel bebas independen. Cara membandingkan antara tingkat pentingnya hasil tes dengan nilai signifikansi yang digunakan dalam penelitian ini. Uji $F$ digunakan menguji signifikansi pengaruh variabel $\mathrm{X}$ secara terhadap $\mathrm{Y}$ secara bersama- sama $\mathrm{F}=R 2 / k(1-R) 2 /(n-k-1)$.

\section{HASIL DAN PEMBAHASAN}

\section{A. HASIL PENELITIAN}

1. Statistik Deskriptif

Tabel 2. Statistik Deskriptif

\begin{tabular}{|l|r|r|r|r|r|}
\hline & \multicolumn{1}{|c|}{$\mathrm{N}$} & Minimum & Maximum & \multicolumn{1}{c|}{ Mean } & Std. Deviation \\
\hline Kepuasan Konsumen (X1) & 100 & 2.00 & 5.00 & 4.1000 & .62765 \\
PX1.1 & 100 & 2.00 & 5.00 & 4.0500 & .72995 \\
PX1.2 & 100 & 3.00 & 5.00 & 4.0500 & .65713 \\
PX1.3 & 100 & 1.00 & 5.00 & 3.5300 & .88140 \\
Loyalitas Konsume (X2) & 100 & 1.00 & 5.00 & 3.3000 & .81029 \\
Px2.1 & 100 & 2.00 & 5.00 & 3.8200 & .77041 \\
Px2.2 & 100 & 3.00 & 5.00 & 4.3400 & .58981 \\
Px2.3 & 100 & 2.00 & 5.00 & 4.4500 & .62563 \\
Keputusan Pembelian Online (Y) & 100 & 1.00 & 5.00 & 4.1600 & .74833 \\
PY1 & 100 & & & & \\
PY2 & & & & \\
PY3 & & & & \\
Valid N (listwise) & & & & \\
\end{tabular}

Sumber dari pengolahan data primer 2021

\section{Hasil Uji Validitas dan Reabilitas}

Dalam uji validitas instrumen penelitian dilakukan dengan menggunakan teknik Product Moment (Pearson) antara setiap item mengukur skala dengan skor skala penuh. Kriteria yang digunakan adalah jika koefisien korelasi dari total artikel lebih besar dari nilai $r$ tabel, item item yang dimaksud dapat dinyatakan valid atau tidak valid (Sunyoto, 2007: 79). Responden, sebesar 150, bisa mendapatkan derajat bebas $(\mathrm{df}) \mathrm{n}-2(100-2=98)$. Untuk $\mathrm{df}=98$, dan nilai alpha $5 \%$ (dua sisi), yang akan dinyatakan valid, total koefisien korelasi elemen harus lebih besar dari 0,3. Dari tabel di atas, dapat disimpulkan bahwa semua elemen instrumen penelitian dinyatakan valid karena nilai $r$ item-total yang lebih besar dari $r$ tabel. Dengan demikian tersebut kuesioner dinyatakan valid.. Dengan demikian, kuesioner dinyatakan valid. 
Tabel 3. Hasil Uji Validitas Instrumen Penelitian Correlations

\begin{tabular}{|c|c|c|c|c|}
\hline & & $\begin{array}{c}\text { Kepuasan } \\
(\mathrm{X} 1)\end{array}$ & $\begin{array}{l}\text { Loyalitas } \\
\text { (X2) }\end{array}$ & $\begin{array}{c}\text { Keputusan } \\
\text { Pembelian (Y) }\end{array}$ \\
\hline \multirow{3}{*}{$\begin{array}{l}\text { Kepuasan } \\
\text { (X1) }\end{array}$} & Pearson Correlation & 1 & $.680^{* *}$ & $.575^{\star \star}$ \\
\hline & Sig. (2-tailed) & & .000 & .000 \\
\hline & $\mathrm{N}$ & 100 & 100 & 100 \\
\hline \multirow{3}{*}{$\begin{array}{l}\text { Loyalitas } \\
\text { (X2) }\end{array}$} & Pearson Correlation & $.680^{* \star}$ & 1 & $.599^{* *}$ \\
\hline & Sig. (2-tailed) & .000 & & .000 \\
\hline & $\mathrm{N}$ & 100 & 100 & 100 \\
\hline \multirow{3}{*}{$\begin{array}{l}\text { Keputusan } \\
\text { Pembelian } \\
\text { (Y) }\end{array}$} & Pearson Correlation & $.575^{\star \star}$ & $.599^{\star \star}$ & $\overline{1}$ \\
\hline & Sig. (2-tailed) & .000 & .000 & \\
\hline & $\mathrm{N}$ & 100 & 100 & 100 \\
\hline
\end{tabular}

Dalam Uji reliabilitas instrumen dilakukan dengan menggunakan teknik Cronbach Alpha. Uji signifikansi dilakukan pada tingkat signifikansi 0,05 , yang berarti bahwa jika nilai alfa lebih besar dari nilai $r$ kritis saat produk, dikatakan bahwa instrumen dapat diandalkan. Setelah menguji validitas, elemen atau item-item yang tidak valid dihilangkan dan elemen yang valid dimasukkan ke dalam tes reliabilitas. Jadi, apa yang akan dihitung ada elemen pertanyaan, karena semua item valid dan dapat digunakan. Hasil analisis reliabilitas instrumen menggunakan SPSS berdasarkan kriteria.

Cronbach's Alpha disajikan dalam Tabel 4. berikut ini.

Tabel 4. Reliability Statistics

\begin{tabular}{|r|r|}
\hline Cronbach's Alpha & N of Items \\
\hline .893 & 6 \\
\hline
\end{tabular}

Sumber: Data Primer diolah, 2021

\section{Uji Asumsi Klasik}

Menurut Sunyoto (2007: 89 - 105), persamaan regresi yang baik adalah persamaan yang memenuhi asumsi berikut: tidak terjadi multikolinenalitas, tidak terjadi heteroskedastisitas, data tersebut didistribusikan secara normal. Penelitian ini akan terlihat dalam hal persamaan regresi, memenuhi atau tidak mematuhi asumsi.

a. Hasil Uji Asumsi Klasik Multikolinieritas

Tabel 5. Uji Multikolineritas Coefficients $^{\mathrm{a}}$

\begin{tabular}{|c|c|c|c|c|c|c|c|c|}
\hline & \multirow[b]{2}{*}{ Model } & \multicolumn{2}{|c|}{$\begin{array}{l}\text { Unstandardized } \\
\text { Coefficients }\end{array}$} & \multirow{2}{*}{$\begin{array}{c}\begin{array}{c}\text { Standardized } \\
\text { Coefficients }\end{array} \\
\text { Beta }\end{array}$} & \multirow[b]{2}{*}{$\mathrm{t}$} & \multirow[b]{2}{*}{ Sig. } & \multicolumn{2}{|c|}{$\begin{array}{l}\text { Collinearity } \\
\text { Statistics }\end{array}$} \\
\hline & & B & Std. Error & & & & Tolerance & VIF \\
\hline \multirow[t]{3}{*}{1} & (Constant) & 6.197 & .887 & & 6.985 & .000 & & \\
\hline & Kepuasan (X1) & .287 & .098 & .311 & 2.928 & .004 & .537 & 1.861 \\
\hline & Loyalitas (X2) & .306 & .084 & .387 & 3.645 & .000 & .537 & 1.861 \\
\hline
\end{tabular}

a. Dependent Variable: $\mathrm{Y}$

Sumber: Data Primer diolah, 2021

Dari output VIF hitung (VIF Kepuasan $=1.861$, VIF Loyalitas=1.861,), semuanya kurang dari 10, maka dapat disimpulkan bahwa antar variabel bebas tidak terjadi Multikolinieritas. 
b. Hasil Uji Asumsi Klasik Heteroskedastisitas

Tabel 6. Uji Heteroskedastisitas Coefficients $^{\mathbf{a}}$

\begin{tabular}{|c|c|c|c|c|c|}
\hline \multirow[b]{2}{*}{ Model } & \multicolumn{2}{|c|}{ Unstandardized Coefficients } & $\begin{array}{c}\text { Standardized } \\
\text { Coefficients }\end{array}$ & \multirow[b]{2}{*}{$\mathrm{t}$} & \multirow[b]{2}{*}{ Sig. } \\
\hline & $\mathrm{B}$ & Std. Error & Beta & & \\
\hline $1 \quad$ (Constant) & 1.559 & .551 & & 2.828 & .006 \\
\hline Kepuasan (X1) & -.029 & .061 & -.066 & -.479 & .633 \\
\hline Loyalitas (X2) & -.028 & .052 & -.073 & -.532 & .596 \\
\hline
\end{tabular}

a. Dependent Variable: Abs_res

Kedua variabel menunjukkan nilai signifikansi diatas 0,05. Variabel kepuasan konsumen (X1) sebesar 0,633, dan variabel loyalitas konsumen 0,596. Hal ini dapat dimaknai bahwa kedua variabel tidak terjadi heteroskedastisitas.

c. Hasil Uji Asumsi Klasik Normalitas

Tabel 7. Uji Normalitas

One-Sample Kolmogorov-Smirnov Test

\begin{tabular}{|ll|r|}
\hline & & \multicolumn{2}{|c|}{ Unstandardized Residual } \\
\hline $\mathrm{N}$ & & 100 \\
Normal Parameters $^{\mathrm{a}, \mathrm{b}}$ & Mean & .0000000 \\
& Std. & 1.17163403 \\
& Deviation & .058 \\
Most Extreme & Absolute & .037 \\
Differences & Positive & -.058 \\
& Negative & .058 \\
Test Statistic & & $.200^{\mathrm{c}, \mathrm{d}}$ \\
\hline
\end{tabular}

a. Test distribution is Normal.

b. Calculated from data.

c. Lilliefors Significance Correction.

$\mathrm{d}$. This is a lower bound of the true significance.

Hasil uji asumsi klasik sehubungan dengan uji normalitas menunjukkan bahwa data memiliki tingkat signifikansi 0,200. Ini menunjukkan bahwa tingkat signifikansi yang dihasilkan lebih besar dari 0,05. Oleh karena itu, data yang dianalisis dalam penelitian ini didistribusikan secara normal.

\section{Uji Hipotesis}

a. Uji Secara Parsial $(\mathbf{U j i}-\mathbf{t})$

Tabel 8. Uji Secara Parsial (Uji - t)

Coefficients $^{\mathbf{a}}$

\begin{tabular}{|c|c|c|c|c|c|c|c|c|}
\hline \multirow[b]{2}{*}{ Model } & \multicolumn{2}{|c|}{$\begin{array}{c}\text { Unstandardized } \\
\text { Coefficients }\end{array}$} & \multirow{2}{*}{$\begin{array}{c}\text { Standardized } \\
\text { Coefficients } \\
\text { Beta }\end{array}$} & \multirow[b]{2}{*}{$t$} & \multirow[b]{2}{*}{ Sig. } & \multicolumn{3}{|c|}{ Correlations } \\
\hline & B & $\begin{array}{l}\text { Std. } \\
\text { Error }\end{array}$ & & & & $\begin{array}{l}\text { Zero- } \\
\text { order }\end{array}$ & Partial & Part \\
\hline $1 \quad$ (Constant) & 6.197 & .887 & & 6.985 & .000 & & & \\
\hline Kepuasan (X1) & .287 & .098 & .311 & 2.928 & .004 & .575 & .285 & .228 \\
\hline Loyalitas (X2) & .306 & .084 & .387 & 3.645 & .000 & .599 & .347 & .284 \\
\hline
\end{tabular}

a. Dependent Variable: $Y$ 
Dari data table diatas, maka dapat disimpulkan :

1. Pengaruh $\mathrm{X} 1$ terhadap $\mathrm{Y}$ dengan nilai t-hitung sebesar $2.928>$ t-tabel 1,976 dan tingkat signifikansi $0,004<0,05$. Berdasarkan hasil analisis regresi berganda pada tabel di atas, kemudian dilakukan uji $\mathrm{t}$ dapat disimpulkan bahwa variabel kepuasan (X1) berpengaruh positif terhadap keputusan pembelian online. Dengan demikian dapat dikatakan bahwa Hipotesis 1 menyatakan bahwa "kepuasan pelanggan akan mempengaruhi positif dan signifikan terhadap keputusan pembelian online Grab"..

2. Pengaruh $\mathrm{X} 2$ terhadap $\mathrm{Y}$ dengan nilai t-hitung sebesar 3.645 $>\mathrm{t}$-tabel 1,976 dan tingkat signifikansi $0,000<0,05$. Berdasarkan hasil analisis regresi berganda pada tabel diatas dan kemudian uji-t dapat disimpulkan bahwa variabel loyalitas (X2) secara parsial berpengaruh positif dan signifikan terhadap keputusan pembelian online.

\section{a. Uji Secara Parsial (Uji-F)}

Tabel 9. Hasil Uji Simultan (Uji-F)

\begin{tabular}{|ll|r|r|r|r|c|}
\hline \multicolumn{7}{|c|}{ ANOVA $^{\mathrm{a}}$} \\
\hline Model & \multicolumn{1}{|c|}{$\begin{array}{c}\text { Sum of } \\
\text { Squares }\end{array}$} & df & Mean Square & F & Sig. \\
\hline 1 & Regression & 94.850 & 2 & 47.425 & 33.850 & $.000^{\mathrm{b}}$ \\
& Residual & 135.900 & 97 & 1.401 & & \\
& Total & 230.750 & 99 & & & \\
\hline
\end{tabular}

a. Dependent Variable: Y

b. Predictors:(Constant),X2,X1

Dari hasil uji F, di dapat F-hitung bernilai 33.850 dengan nilai sig 0,00, untuk F-tabel sebesar 1,976. Dari hasil diatas maka F-hitung lebih besar dari F-tabel $(33.850 \geq 1,976)$, sehingga H0 ditolak. Jadi dapat disimpulkan bahwa untuk kepuasan dan loyalitas dengan bersamaan memiliki pengaruh yang cukup siginifikan terhadap keputusan pembelian online (grab).

\section{Koefisien Determinasi}

Tabel 10. Hasil Uji Koefisien Determinasi (Uji-D)

\begin{tabular}{|l|c|r|r|r|}
\hline Model & R & R Square & $\begin{array}{c}\text { Adjusted R } \\
\text { Square }\end{array}$ & $\begin{array}{c}\text { Std. Error of } \\
\text { the Estimate }\end{array}$ \\
\hline 1 & $.641^{\mathrm{a}}$ & .411 & .399 & 1.18365 \\
\hline
\end{tabular}

a. Predictors: (Constant), X2, X1

Dari hasi SPSS tersebut, diketahui secara kontribusi menerangkan hasil Adjusted $R$ Square (R2) atau koefisien - koefisien adalah 0,411. Nilai tersebut menjelaskan bahwa keputusan pembelian/penggunaan online aplikasi grab dapat diperkuat dari kepuasan dan loyalitas pelanggan (variabel independen) dengan nilai $41,1 \%$. Selebihnya 58,9\% dipengaruhi oleh faktor lain, hal ini menunjukkan dimana makin besar nilai yang diperoleh dapat memicu model regresi semakin akurat untuk mengestimasi keputusan pembelian/penggunaan online aplikasi grab.

\section{KESIMPULAN}

Kebanyakan responden yang pernah membeli atau sekedar menggunakan aplikasi grab adalah perempuan dan yang berusia $>21$ tahun serta mayoritas responden merasa puas terhadap layanan 
online grab,dimana terdapat pengaruh positif dan signifikan kepuasan pelanggan terhadap keputusan pembelian atau penggunaan online pada aplikasi tranportasi grab. Dimana hal ini menunjukkan bahwa semakin baik kepuasan pelanggan maka semakin tinggi keputusan pembelian atau penggunaan online pada aplikasi tranportasi grab yang dirasakan responden di aplikasi grab, selain itu terdapat pengaruh positif variabel loyalitas terhadap keputusan pembelian atau penggunaan online pada aplikasi tranportasi grab. Dalam hal ini menunjukkan bahwa semakin tinggi loyalitas pelanggan maka semakin tinggi keputusan pembelian atau penggunaan online pada aplikasi tranportasi grab. Variabel kepuasan, dan loyalitas, secara simultan atau secara bersamasama berpengaruh positif dan signifikan terhadap keputusan pembelian atau penggunaan online pada aplikasi tranportasi grab. Hal ini menunjukkan semakin baik dan tinggi kepuasan yang dirakanan pelanggan akan meningkatkan loyalitas pelanggang dalam menggunakan aplikasi grab, sehingga akan meningkatakan keputusan pembelian atau penggunaan online pada aplikasi tranportasi grab yang dirasakan responden pengguna aplikasi grab. Berdasarkan hasil uji koefisien determinasi, nilai adjusted $\mathrm{R}^{2}$ sebesar 0,411 atau 41,1\%. Hasil pengujian ini menunjukkan bahwa $41,1 \%$ variabel keputusan pembelian atau penggunaan online pada aplikasi tranportasi grab dapat dijelaskan oleh variabel kepuasan, dan loyalitas. Sedangkan sisanya sebesar 58,9\% dapat dijelaskan oleh variabel-variabel lain yang tidak dimasukkan dalam model penelitian.

\section{DAFTAR PUSTAKA}

[1] Bakti, I Gede Mahatma Yuda \& Sumaedi Sik. 2012. An Analysis of Library Customer Loyalty The Role of Service Quality and Customer Satisfaction, a Case Study in IndonesiaLibrary Management. Indonesian Institute of Sciences, Tangerang Selatan, Indonesia. Vol. 34 No. 6/7.

[2] Donald, R. Cooper \& Schindler Pamela S,2017, Metode Penelitian Bisnis, Salemba Empat, Jakarta.

[3] Dolarslan, Emre S. 2014. Assessing The Effects of Satisfaction and Value on Customer Loyalty Behaviors in Service Environments High-speed Railway in Turkey as a Case Study Management Research Review. Department of Business Administration/Marketing, Çankiri Karatekin University, Çankiri, Turkey. Vol.37No.8.

[4] Gumilang, bintang C. 2017. Pengaruh Kepuasan dan Loyalitas Pelanggan Terhadap Keputusan Menggunakan Jasa Layanan Ojek Online di Wilayah Eks Karesidenan Surakarta. Universitas Muhammadiyah Surakarta.

[5] Hardiati, Sri \& Sarwi Ruci. 1999. Analisis Kinerja Kualitas Pelayanan Terhadap KepuasanPelanggan pada Telkomsel Malang Area. Jurnal Manajemen dan Kewirausahaan Vol. 1, No. 1, hal 56-64.

[6] Kotler, Philip dan Gary Amstrong, 2008, Prinsip-Prinsip Pemasaran, EdisiKeduabelas, Jilid 1, Penerbit Erlangga, Jakarta.

[7] Kotler, Philip, 2001, Manajemen Pemasaran di Indonesia : Analisis,Perencanaan, Implementasi dan Pengendalian, Salemba Empat, Jakarta.

[8] Kotler, Philip, 2005, Manajemen Pemasaran, Jilid 1 dan 2, PT. Indeks Kelompok Gramedia, Jakarta

[9] Kursunluoglu, Emel. 2014. Shopping Centre Customer Service: Creaing Customer Satis faction and Loyalty. Journal facultyn of Economic and Business Administration Marketing Intelligence \& Planning Vol. 32 No. 4.Yasar University, Izmir, Turkey.2014. 
[10] Sandada, Maxwell. 2015.The Mediating Influence Of Passenger Satisfaction On TheReLationship Between Passenger Loyalty Programmes And Passenger Loyalty. Studia Universitatis Babeș-Bolya Oeconomica, Zimbabwe: University Zimbabwe, Volume 60, Issue 3.

[11] Stanton, William J., 2001, Prinsip Pemasaran, Erlangga, Jakarta.

[12] Sugiyono. 2015. Memahami Penelitian Kualitatif. Cetakan Kesebelas. Bandung: Alfabeta.

[13] Sugiyono. 2016. Metode Penelitian Kuantitatif, Kualitatif dan R \& D. Bandung: Alfabeta.

[14] Umar, Husein, 2003, Riset Pemasaran dan Perilaku Konsumen, GramediaPustaka Utama, Jakarta. 